\title{
Indian Journal of
}

\section{LANGUAGE AND LINGUISTICS}

\section{A Linguistic Analysis of 'Pet Names' in Nzema: A Morphosyntactic Description}

\section{Mohammed Yakub *}

University of Education, Winneba, Ghana

*Corresponding author Email: yakubm88@gmail.com

DOI: https://doi.org/10.34256/ijll2011

Published: 26-09-2020

Abstract: In the field of Onomastics, many researchers have delved into the study of personal names, place names, church names and school names, among others. This paper gathers another exciting data, (i.e. names that are ascribed to pets in Nzema society) and seeks to examine the morpho-syntactic features of the 'pet names'. The paper employs the qualitative research approach in providing a descriptive analysis of the linguistic properties that feature in pet names among the people of Nzema. In this paper, ninety (90) pet names are discussed. Relying on Haspelmath's notion of Framework-free Theory of Grammatical Analysis, the paper demonstrates that the morphological structures of Nzema pet names include single root morphemes, lexical compounding, derivational and inflectional processes, lexical borrowing, and reduplication. These word formation processes are accompanied by some phonological processes such as vowel elision and harmony. At the syntactic/sentential level, the pet names function as simple declarative sentences, imperatives and interrogatives. Compound and complexembedded clauses were also prevalent in the structure of the pet names. It is ascertained that these pet names are grammatically insightful and can provide a window to understanding the morphosyntactic features of the Nzema language.

Keywords: Nzema pet names, Onomastics, Morphophonology, Syntax.

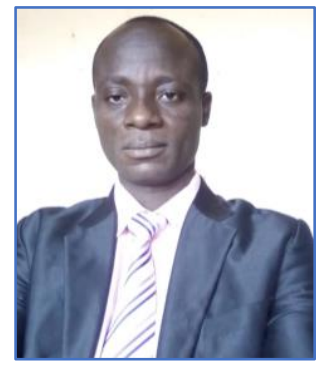

Mr. Mohammed Yakub has M.Phil in Ghanaian Language Studies (Nzema) from the University of Education, Winneba. His areas of research interest are morpho-syntax, cognitive linguistics, anthropological linguistics, ethno-pragmatics and Literature. Some of his previous publications appear in the International Journal of Linguistics and Literature, International Journal of Language and Literature, European Journal of Applied Linguistics Studies and Studies in Literature and Language

\section{Introduction}

Naming is considered as one of the components of a cultural script; which is an important practice in many societies (Caesar, 2019). Mensah and Rowan (2019a) contend that names are conventional sings which help to preserve cultural identity and indigenous linguistic heritage. This position may give a signal that, across cultures, linguistic elements could manifest in the names that are bestowed on persons, animals, places and things. A personal name, for instance, describes the name bearer, the language from which the name is derived, and the society that assigns the name (Mphande, 2006). Suzman (1994) and Agyekum (2006) share the view that personal names serve as pointers which can be given to people based on some circumstances that were relevant at the time of their birth. This can suggest that names, especially in the African context, may not be given to persons haphazardly, but may be assigned to persons based on past and present experiences of the name-giver. For instance, in providing a sociocultural account of personal names among the Tiv people, Mensah and Rowan 
(2019b: 227) aver that "personal names mirror indigenous viewpoints that reflect parents' hopes for the namebearers' future wellbeing". The authors further note that personal names can portray a wide range of emotional sentiment patterns in the context of the Tiv traditional society. African names have communicative contents (Obeng, 1998; Batoma, 2009) which tell stories about past occurrences, experiences and circumstances of birth. This is to say that names can serve as social dialogues and cultural narratives (Mensah and Rowan, 2019b) which provide significant information on historical events, and can largely reflect the beliefs, values and general worldview of a particular cultural group.

The Nzema people, like in many other diverse cultures, hold the practice of naming in high esteem. Among the Nzema, names such as Kumaswie 'grave is finished' and TEnlaaze 'be seated' are 'death-prevention names' given to children whose preceding siblings died shortly after they were born. Personal names like Ndabia and Ndabsla are also used in Nzema culture to refer to male and female twins respectively. The Nzema refer to a person born on Sunday as Koasi and Akasi (see Kwaw, 2008a) for male and female respectively. Other allusiveproverbial names like $\varepsilon k \varepsilon y \varepsilon b o \varepsilon$ 'you shall succeed', Enzemetianu 'you do not know my intentions/determinations' and Brwieka 'there is no more comment' are usually given to people to portray the name-giver's feelings and beliefs.

However, going beyond the phenomenon of personal naming, the Nzema also relish in assigning names to their pets for several personal reasons based on certain philosophical issues and life experiences of the pet-owner (in this case the name-giver); though not all people may name their pets ${ }^{1}$. Among the Nzema people, most of these names that are given to pets appear to be proverbial; characterised by pragmatic inferences and presuppositions which the name-givers use as a communicative channel to cast some sort of insinuation directed at some individuals. In this paper, however, our interest would not be on the socoi-cultural aspects of pet naming, which may concern the purpose and reason behind the choice of names that are given to the pets; rather, we would be concerned with some linguistic elements of the pet names; finding out whether the names reveal certain peculiar structural properties or may conform to and provide a window to the grammatical description of the Nzema language.

Ephratt (1986) and Obeng (2001) observe that personal names are governed by grammatical rules, which are structurally made up of single words, phrases and sentences. This observation largely influences the current study; hypothesising that, similar grammatical rules can apply to the structure of Nzema pet names. Thus, the paper tries to explicate how these names are linguistically insightful, and are worth analysing from a morphosyntactic perspective.

\subsection{Nzema as a People and Language}

The Nzema people, who are located in the Western Region of Ghana, speak a language that is also called Nzema (Annan, 1980). Nzema belongs to the Niger-Congo Kwa language family. Besides its dominant speakers in the South-West part of the Western Region of Ghana, Nzema is also spoken in some parts of La Côte d'Ivoire (Kwesi, 1992). Most of the Nzema people are farmers who engage in subsistence agriculture. Besides farming activities, the people also take delight in trading to support their living. According to population estimates available on $31^{\text {st }}$ May, 2012, the total population of Ghana as at $26^{\text {th }}$ September, 2010 was $24,658,823$ people of which

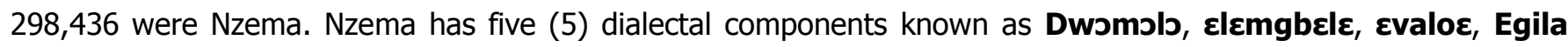
and Adwomolo (Kwaw, 2008a). The Dwomolo dialect has been standardised for literacy; which is studied from Basic (Primary) to Tertiary level.

As part of its grammatical properties, Nzema primarily has the SVO order of clause structure. The basic syllable structure of Nzema is V, CV, and N; where N represents a syllabic nasal (Annan, 1980: 85).

\footnotetext{
${ }^{1}$ In many societies, especially in Africa and perhaps beyond, some people keep domestic animals as pets and companions. Among the Nzema in particular, these animals (e.g. cats, dogs, goats, sheep, monkeys, parrots and domestic chicken) may be kept for pleasure, security, food and income. As people who are predominantly farmers, some Nzema men also rear dogs for hunting. These animals are sometimes given names, which somewhat portray certain philosophical principles and sociocultural worldview of the people.
} 
It is prudent to stress that some phonological processes are indispensable in morphological phenomena such as reduplication and compounding (see Adomako, 2012; 2015; 2017). Thus, I find it worth providing a sketch of the Nzema vowel inventory to enable our audience best appreciate the discussions in section 3 of this paper. Nzema has ten vowels such as $[\mathrm{a}, \varepsilon, \mathrm{e}, \mathrm{i}, \mathrm{J}, \mathrm{o}, \mathrm{u}, \mathrm{v}, \mathrm{I}, \Lambda]$ (Annan, 1980: 8; see also Kwaw, 1999; Arloo, 2016). Figure 1 below further illustrates the Nzema vowel chart:

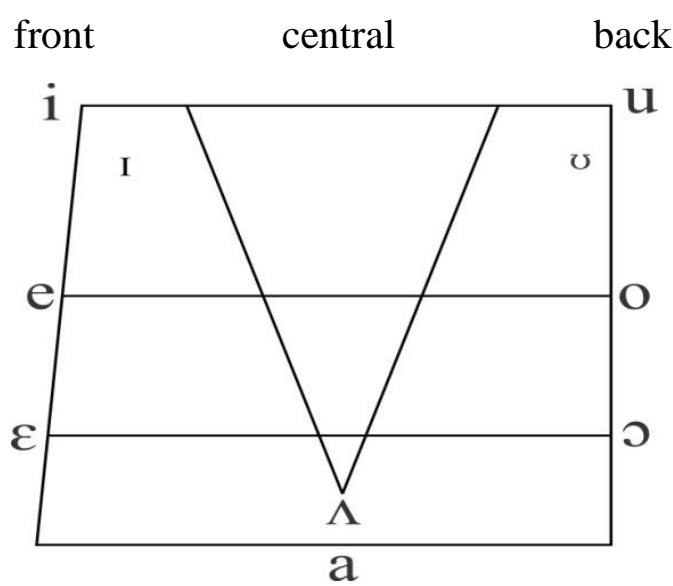

Figure 1 The Nzema vowel chart. (Adopted from Annan, 1980: 15)

Regarding their phonetic features, Annan groups the vowels as follows:

- High vowels $[\mathrm{i}, \mathrm{I}, \mathrm{v}, \mathrm{u}]$

- Mid-high vowels $[\mathrm{e}, \mathrm{o}]$

- Mid-low vowels $[\varepsilon, \wedge, 0]$

- Low vowel [a]

- Rounded/back vowels $[\mathrm{u}, \mho, \mathrm{\jmath}, \mathrm{0}]$

- Spread vowels [i, I, e, $\varepsilon, \wedge$, a]

- Front vowels $[i, \mathrm{I}, \mathrm{e}, \varepsilon$,

- Central vowels $[a, \wedge]$

- $\quad$ ATR (Advanced Tongue Root) $[i, e, u, 0, \Lambda]$

- -ATR (Not advanced Tongue Root) $[\mathrm{I}, \varepsilon, v, 0, \mathrm{a}]$

- Nasalised vowels [i, I, u, v, J, a, ]

- Non-nasalised vowels $[e, \varepsilon, \wedge, 0]$

\subsection{Related Literature: A Cross-Linguístic Overview}

The subject of name as a multidisciplinary field has caught the attention of many philosophers, anthropologists and linguists from various angles. There have been enormous research on names from the perspectives of sociolinguistics (e.g. Egbewogbe, 1977; Agyekum, 2006; Abdul, 2014; Mensah, 2015), sociocultural (see Ansu-Kyeremeh, 2000; Dakubu, 2000; Dominic, 2014), pragmatics (see Obeng, 1998; Batoma, 2009; 2019), morphophonology (Adomako, 2015; 2017), morphosemantics (Olenyo, 2011; Jauro, et al., 2013; Gerba, 2014; Agyekum, 2018; Awukuvi and Israel, 2018), and morphosyntactic (cf. Mensah and Offong 2013; Jindayu, 2013). It needs to be re-echoed that linguistics universality seems to manifest also in the onomastics systems of diverse languages and cultures. This is to say that certain linguistic phenomena are imbued and embedded in the names that are used in many languages and cultures.

In Arabic, for example, Hedden (2007) indicates that most names of persons, places and organisations include the definite article at as part of the name; which could be joined to the following word by a hyphen, as in al-Turabi. The article may also be capitalised as in Al-Waleed and Al-Thani. Hedden observes that compound names written as single-word names also prevail in Arabic, beginning with $A b d$ and followed by the word for God, as in $A b d u l l a h$. $A b d$, which means 'servant', can combine with a word like Rahman, which is a descriptive name (an 
attribute) of God to derive a personal name in Arabic, such as Abdulrahman, meaning 'servant of the merciful' (see Hedden, 2007: 12).

Lawson et al. (2014) also report that French has the tendency to use diminutives extensively. They provide representative diminutive terminations to French names such as eau, elle, el, ot, otte, let, ellet, among others. The authors further note that the tendency of French to stress a final syllable has produced aphesis in many given names, for example; COLAS from NICOLAS and BASTIEN from SEBASTIEN. The addition of the letter "e" to a masculine given name, as the authors reveal, also results in its feminine equivalent as in Denis (male name) to Denise (female name) and Raymond (male name) to Raymonde (female name). This morphophonological process in French names seems to appear similarly in Akan (Twi), a Kwa language of Ghana, which derives 'female-family names' by attaching suffixes such as $\{-\mathbf{a}\}$ or $\{$-aa $\},\{$-waa $\}$ or $\{$-maa $\}$ etc. to the 'male-family names', as exemplified in Ofori (male-family name) becomes Oforiwaa (female-family name) and Frimpon (male-family name) becomes FrImponmaa (female-family name) (see Adomako, 2017). In essence, we find (in the Akan examples) that the male names serve as the base morphemes from which the female names are obtained through suffixation.

In describing the formation of Turkish personal names, Lawson and Sheil (2016) show that the structure of Turkish names may be said to be basically similar to that of English. They explain this by saying that a child receives his given name, say $(X)$ at birth, and his surname is the family name, say $(P)$ of his father. Therefore, Turkish personal names basically have the (XP pattern). The authors state that, predominantly, Turkish names have Arabic-Islamic origin. However, an interesting linguistic (morphophonological) feature of Turkish names is that masculine given names generally end in a consonant as can be seen in Aziz, Mehmed, Fuad, Halid, Nihat, Osman, Yakup etc. (see Lawson and Sheil, 2016: 14). They observe that a few of such names may end in -i, as in Ali, Avni and Hamidi.

Some African languages have also been explored in connection with the linguistic properties that prevail in the onomastic tradition of the people who use those languages. For example, Ogunwale (2012) from a pragmalinguistic perspective examines personal names in Yoruba, a language spoken predominantly in Nigeria. The author discusses how proverbs in the language are 'reduced' to somewhat simple words to fit as personal names in the Yoruba sociocultural setting. This seems to be in line with Yuka's (2008) earlier observation that personal names in Lamnso are characterised by 'economy' of lexical choices, meaning that the names do not usually comprise longer words. Ogunwale (2012) then tells us that the thematic contents of the proverbs in Yoruba are the tokens that become relevant to be used as personal names in the Yoruba society.

Agbo (2014) also investigates the grammatical concept of causativity as it occurs in the 'formation' of personal names in Igbo. In examining the data from a morphosyntactic point of view, the author posits that Igbo personal names have crucial causativasing morphemes, which include; funa, gbo, gbu, me, kwe, kwu and na in their lexicalised forms. The author shows that Igbo word formation processes include prefixation, interfixation and suffixation; and that most of these causative morphemes function similarly (in terms of their distribution) in the structure of the names. The me causativiser, for instance, as Agbo makes us aware, can occur at the initial, medial and final positions of some personal names, as in Meenakaya 'do something by oneself', Emeeanu 'when it is done it is heard' and Kaanaeme 'let us keep doing' respectively (see Agbo, 2014: 21-25).

Specifically, in Ghanaian Languages, a number of studies with regard to names have also been undertaken. One of such influential studies is Nsoh and Atintono's (2010) "Personal names among the Farefari speakers of Northern Ghana". In their paper, the authors bring to the fore the purpose and processes of naming in the Farefari traditional society. They opine that the Farefari names are a reflection of cosmological and sociolinguistic information encoded in surface linguistic structure for the purpose of identifying individuals in the culture. Nsoh and Atintono's paper focuses on two kinds of names, namely; sigere 'names of dead parents or ancestors' and yubo'ore-a 'names given to children immediately after birth'. Importantly, their investigation reveals that personal names in Farfari, especially among Boome, Gurenc, Nankani, and to a lesser extent the Nabt speakers, are morphologically characterised by the prefixation of $\{\mathbf{a}-\}$. This nominalising morpheme, as the authors note, also gives the derived name a 'human feature'. For example, tia 'tree' becomes a-tia 'Atia, a personal name' and sona 'having' becomes a-sona 'Mr. Asona, a personal name' (see Nsoh and Atintono, 2010: 78). 
Another significant contribution is Owu-Ewie's (2014) "Morphosyntactic analysis of some Fante habitation names". In this study, Owu-Ewie informs us that, Fante (a dialect of Akan of Ghana), uses inflectional morphemes like $\{$-nyi\} (representing human and singular as in Ghananyi, meaning a person from Ghana) and \{-fo\} (representing human and plural as in Ghanafo, meaning people from Ghana. He further exemplifies possible reduplicated morphemes in Fante as in $h w \varepsilon$ 'look' which when reduplicated becomes hwehwe 'to search for something' and nsu 'water' also undergoes total reduplication to form nsunsu 'watery/waterlogged'. Thus, in his analysis of the habitation names, some of these word formation processes were pervasive, indicating that Eguafo is a place/habitation name which comprises Egua 'trade' plus the suffix - $f o$ 'plural marker' which together forms Eguafo 'traders' (see Owu-Ewie, 2014: 239). Reduplicated habitation names also emerged, such as abo 'rock' being repeated as in aboabo (Aboabo) 'rocky area'. Some compound habitation names include; (Noun + Noun compound), as in Anoma 'bird'+ bo 'rock' $\rightarrow$ Anomabo 'bird's rock' and (Noun + Postposition compound), as in Bese 'cola' + ase 'down' $\rightarrow$ Besease 'under the cola tree'. At the syntactic level, the habitation names were seen to be structurally simple, compound and complex sentences which perform declarative, imperative and interrogative functions.

Caesar (2019) also looks at the linguistic properties of allusive names in Dangme, focusing on the morphological and syntactic features of the names. Critically assessing the data, the author notes that such allusive-proverbial names can be mono-morphemes which cannot undergo any further division to produce meaningful components. Some single morpheme allusive names identified are; Odehe 'a great one', Sika 'money' and JuEni 'jewellery' among others (see Caesar, 2019: 62). Compound allusive names also showed up, as in Sika 'money' (noun) + tsu 'red' (adjective) $\rightarrow$ Sikatsu 'red money' (God). Structurally, the data showed phrasal, simple and compound sentences as well as complex clauses that are reduced to personal names in the language. Caesar's findings apparently corroborate that of Owu-Ewie as outlined above, since the data analysed in both studies were centred on morphology and syntax.

The bestowal of 'theophoric' names on children in Nzema society has long been a common cultural phenominon. Thus, from a linguistic perspective, Yakub and Mpotsiah (forthcoming) attempt to investigate the structural properties of such 'theophoric' personal names in Nzema, focusing on names that exist with the incorporation of the lexical noun Nyamenle, 'God'. The authors note that, Nyamenle, which refers to God, is lexicalised; constituting two morphological components, such as nya 'leaves/herbs' and menle 'owner'. Hence, Nyamenle means the 'owner of herbs'. The syntactic analysis revealed that Nyamenle is usually concatenated with other lexical categories such as verbs, pronouns and other post-positional elements to constitute personal names that form complete syntactic strings. The study also demonstrated that such 'theophoric' names satisfy sentential structures and patterns; such as simple, compound and complex (conditional) sentences; including declarative and imperative sentence functions. Forming part of such personal names, Nyamenle, can perform grammatical functions such as Subject-agent and as Direct object-patient; occurring predominantly in names that have simple sentence constructions. Other interesting syntactic features such as focus marking and serial verb constructions were noted to be prevalent in Nzema personal names involving Nyamenle 'God'. The study further showed that the Nzema use Nyamenle as part of their personal names to communicate diverse human experiences; based on their socio-cultural values, belief system and traditional worldview. In this current study, however, it will be observed that 'names of pets' among the Nzema are rather obtained from a variety of linguistic processes; which demonstrate interesting grammatical features of the Nzema language. More significantly, it will be appreciated that, unlike 'theophoric' personal names, for instance, 'pet names' in Nzema can be derived from a greater variety of morphological processes.

All these previous contributions have some resemblance with the present study; however, the works of Owu-Ewie (2014) and Caesar (2019) seem to be closely linked to this study, and so they have a significant assistance to the analysis therein. It should be stressed that these previous works among others can provide evidence that cross-cultural/linguistic studies on onomastics abound. However, the literature so far, at least to the best of my knowledge, has not recorded much on grammatical description of names that are assigned to domestically tamed animals. Hence, the present study attempts to shift the attention from 'place names' (toponymy) and 'personal names' (anthroponymy) with the intent to providing a morphosyntactic description of pet names among the Nzema; and to extend the frontiers of the existing studies in the onomastics literature in general. 


\section{THE DATA AND THEORETICAL FRAMEWORK}

Most of the pet names used for analysis/discussions in this paper were tapped from the work of Yakub (2019a). Yakub's work served as a secondary material which was consulted for some data for this paper because it had a rich set of data ${ }^{2}$ through which the author critically examined the purpose of pet naming among the Nzema; finding answers to why some people do ascribe certain names to their pets in Nzema socio-cultural setting. Additional data were obtained by contacting ten (10) final year students who offer Nzema as an elective subject at Baidoo Bonsoe Senior High Technical School in the Ahanta West Municipality in the Western Region of Ghana. I tasked each of the 10 participants to write as many pet names as they would recall. These students were purposively selected because they had lived in indigenous Nzema communities where people tamed animals as pets and sometimes gave names to such animals. The data were later assembled, finding the common occurrences with regard to the morphosyntactic features of the pet names. These were then categorised for analysis.

The analysis of data in this paper is underpinned by the central tenet of Haspelmath's (2008) Frameworkfree Theory of Grammatical Description. According to Haspelmath, Framework-free Theory is a grammatical theory, (i.e. a theory of morphosyntax); which posits that a language can be adequately described in its own terms, without necessarily being strictly governed by any theoretical framework. Haspelmath (2008: 1) argues against the use of restrictive theoretical framework by noting that when a grammatical description is based on a particular theoretical framework, certain 'self-evident' assumptions may lead to a distorted description of a language. This can imply that in employing Framework-free Grammatical Theory for linguistic analysis, a researcher would be guided by the 'natural' data and be able to do accurate description of the data (language) as it appears in its own right. In essence, I find it appropriate and effective to ground the morphosyntactic analysis of Nzema pet names in the Framework-free Grammatical Theory; since it is descriptive and seeks to allow a 'free' and 'unrestricted' analysis of a linguistic phenomenon.

\section{DATA PRESENTATION AND DISCUSSION}

In this section, I present and analyse the data for the study. This is done, situating the discussions in the grammatical domain of the Nzema language. The discussions first begin with examining the morphological structures of the pet names, which include single root morphemes (free morphemes), compounding, inflectional and derivational processes, lexical borrowing, and reduplication. In the morphological analysis, some emerging phonological issues are also addressed. The syntactic properties of the pet names are further examined.

\subsection{MORPHOLOGICAL ANAL YSIS OF NZEMA 'PET NAMES'}

\subsubsection{Pet Names as Single Root Morphemes}

Some of the pet names, as the data demonstrated, were morphologically single root words; which are obviously nouns used to identify the tamed animals. Examples of such pet names which are morphologically single root (free morphemes) are shown in table $1(\mathrm{a}-\mathrm{h})$ :

Table 1 Nzema pet names as single root morphemes

\begin{tabular}{|c|c|}
\hline Pet name & English gloss \\
\hline a. Abotane & Patience \\
\hline b. Adom & Grace \\
\hline c. Ewiade & (The) world \\
\hline d. Anyiamgba & Disgrace \\
\hline e. Pelepsle & Justice \\
\hline f. $\quad$ Ezukoa & Money/wealth \\
\hline g. $\varepsilon y \varepsilon v o l \varepsilon$ & Stranger \\
\hline h. Nyane & Pain/suffering \\
\hline
\end{tabular}

\footnotetext{
2 The author used an ethnographic approach, through interviews to elicit information from indigenous/native Nzema speakers
} who owned pets that had been given names. 
In table 1, we find that all the pet names (in a-h) are single root morphemes; they do not have affixes attached to them. These pet names are mono-morphemic words that cannot undergo any further division to produce meaningful components.

\subsubsection{Nzema 'Pet Names' as Compound Words}

Compounding is a morphological process where two or more free morphemes are joined to form one new word (cf. Baruah, 1991; Thakur, 1997; Wiredu, 1999). Yule (2010: 55) defines compounding as the process of combining two separate words to produce a single form. A compound word in Nzema also consists of at least two words (free morphemes), combined to form a new word. It can therefore be made up of (Noun + Adjective), $($ Noun + Noun), (Verb + Verb), (Verb + Adjective), (Verb + Adverb) etc. (see Baruah, 1991: 85). In the data for this study, most Nzema pet names were noted to be compound words. Some examples are examined in tables (27):

Table 2 Noun + Adjective Compound

\begin{tabular}{|c|c|c|c|}
\hline Pet name & $\begin{array}{l}\text { Morphological component } \\
\quad(\text { Noun + Adjective) }\end{array}$ & $\begin{array}{l}\text { English gloss } \\
\text { Noun +Adjective }\end{array}$ & $\begin{array}{l}\text { Free English } \\
\text { translation }\end{array}$ \\
\hline a. Sonlabile & sonla + bile & human + black & black man (African) \\
\hline b. Dumapkalع & duma + kpale & name + good & good name \\
\hline c. Agyalctane* & agyal $\varepsilon+$ ctane & marriage + bad & bad marriage \\
\hline d. Ezukoevinli* & ezukoa + evinli & money + dirty & $\begin{array}{l}\text { dirty money /money } \\
\text { from evil source }\end{array}$ \\
\hline
\end{tabular}

In table (2c), we observe vowel elision. The front mid-low vowel $/ \varepsilon /$, which occurs at word final position of agyal $\varepsilon$ 'marriage', also begins the adjective $\varepsilon$ tane 'bad'. When these two words agyale and $\varepsilon$ tane form a compound word as in the pet name Agyalctane 'bad marriage', one of the $/ \varepsilon /$ elides in order to break the vowel sequence. This phonological phenomenon, according to Nyame (2019), is a mechanism to resolve vowel hiatus in Nzema ${ }^{3}$. In (2d), the central low vowel /a/, which occurs at word final position as in ezukoa 'money' undergoes elision when it forms a sequence with the front mid-high vowel /e/, which occurs at word initial position of the adjective evin/i 'dirty'. This results in /oe/ vowel sequence as can be seen in the pet name Ezukoevinli 'dirty money'. The /oe/ sequence indicates vowel harmony in the sense that both /o/ and /e/ (see below figure 1) have common phonetic features; such as +ATR and +mid-high vowels.

Table 3 Noun + Noun Compound

\begin{tabular}{|c|c|c|c|}
\hline Pet name & $\begin{array}{c}\text { Morphological component } \\
\text { (Noun + Noun) }\end{array}$ & $\begin{array}{l}\text { English gloss } \\
\text { Noun + Noun }\end{array}$ & $\begin{array}{l}\text { Free English } \\
\text { translation }\end{array}$ \\
\hline a. Nyamenlemeke & Nyamenle + mek & God + time & God's time (is best) \\
\hline b. Ezukoedweke* & ezukoa + edwekc & money + issue & money matter \\
\hline c. Ehyiedwعkع* & 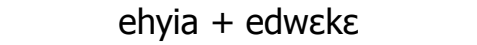 & poverty + issue & poverty matter \\
\hline
\end{tabular}

In table (3b), a similar phonological process takes place as observed earlier in (2d). In (3b), the central low vowel /a/, which occurs at word final position of the noun ezukoa 'money' is elided in an environment when it

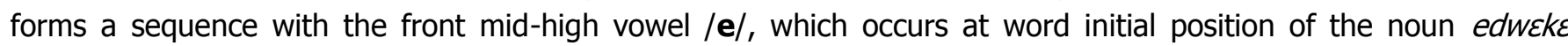
'issue/matter'.

This creates the compound pet name EzukoedwekE 'money matter'; where we can realise harmony between the vowels /o/ and /e/ which form the sequence/cluster. In (3c), the central low vowel /a/ at word final position as in ehyia 'poverty' undergoes elision in an environment when /a/ co-occurs with /e/ appearing at the

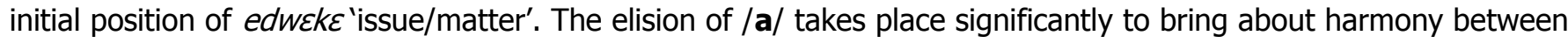

${ }^{3}$ This is, however, not to say that sequence of vowels do not exist in the lexicon of Nzema. In fact, there are possible

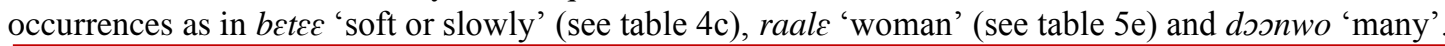


the two vowels /i/ and /e/; which form a sequence as in the pet name Ehyiedweks 'poverty matter'. The harmony is achieved in the sense that /ie/ share the phonetic features + ATR, +front, and +spread.

Another kind of lexical compounding that emerged out of the data was Verb + Adverb combination. This comprised a root verb + an adverb of time or manner, as illustrated below in table 4:

Table 4 Verb + Adverb Compound

\begin{tabular}{|c|c|c|c|}
\hline Pet name & $\begin{array}{c}\text { Morphological component } \\
\text { (Verb + Adverb) }\end{array}$ & $\begin{array}{c}\text { English gloss } \\
\text { Verb + Adverb }\end{array}$ & $\begin{array}{l}\text { Free English } \\
\text { translation }\end{array}$ \\
\hline a. Kakyedcba & kakye + dcba & remember + old & recall previous events \\
\hline b. Dwenlekenlebie & dwenle + kenlebie & think + future & think about the future \\
\hline 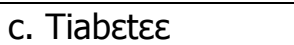 & 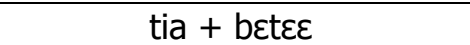 & walk + slowly & be patient in life \\
\hline
\end{tabular}

Verb + Noun compound pet names also emerged. In this lexical combination, a root verb and a root noun are involved. Some examples from the data are presented in table 5:

Table 5 Pet names with verb + noun compound

\begin{tabular}{|c|c|c|c|}
\hline Pet name & $\begin{array}{c}\text { Morphological component } \\
\text { (Verb + Noun) }\end{array}$ & $\begin{array}{l}\text { English gloss } \\
\text { Verb + Noun }\end{array}$ & Free English translation \\
\hline a. Bizanyamenle & biza + Nyamenle & ask + God & seek direction from God \\
\hline b. Sonlenyamele & sonle + Nyamenle & worship + God & worship God \\
\hline c. Faadwenle* & fa + adwenle & take + mind & be wise \\
\hline d. Sulosonla & sulo + sonla & fear + human & fear human being \\
\hline e. Suloraale* & sulo + raale & fear + woman & fear woman \\
\hline f. Sklengoane & scl $\varepsilon+$ ngoane & beg + life & seek long life \\
\hline
\end{tabular}

In table (5c) above, the central low vowel /a/ occurs at syllable final of the CV verb fa 'take' and also occurs at the initial position of the noun adwenle 'mind'. This has resulted in a sequence of vowel; that is /aa/ as in faadwenle 'take mind' (be wise). This phenomenon, according to Owu-Ewie (2014: 239), can also be referred to as vowel lengtheningt. In (5e), we can equally observe the sequence of /aa/ in the noun raale 'woman'. However, this may not be triggered by any phonological condition because the orthography of Nzema already permits a repetition of the vowel in such a lexical noun.

The data further revealed Verb + Adjective combination. In this compound structure, the pet names comprised a root verb and an adjective (Verb + Adjective). Some examples are illustrated in table 6:

Table 6 Pet names with verb + adjective compound

\begin{tabular}{|c|c|c|c|}
\hline Pet name & $\begin{array}{l}\text { Morphological component } \\
\text { (Verb + Adjective) }\end{array}$ & $\begin{array}{l}\text { English gloss } \\
\text { Verb+Adjective }\end{array}$ & $\begin{array}{l}\text { Free English } \\
\text { translation }\end{array}$ \\
\hline a. Diboc & $\mathrm{di}+\mathrm{bo \varepsilon}$ & eat + good & do good \\
\hline b. Dwenlekpale & dwenle + kpal $\varepsilon$ & think + proper & think positively \\
\hline 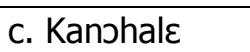 & ka + nohal $\varepsilon$ & say + true & speak the truth \\
\hline
\end{tabular}

\footnotetext{
${ }^{4}$ However, this may not necessarily be a compensatory lengthening since there is no elision of an adjacent segment in the process of the lengthening of vowel sound.
} 
The next discussion has to do with pet names that combine a root verb and an indefinite quantifier. Some of such compound structures which manifested in the data are tabulated below in 7:

Table 7 Verb + Indefinite quantifier

\begin{tabular}{|l|c|r|l|}
\hline Pet name & $\begin{array}{l}\text { Morphological component } \\
\text { (Verb + Indefinite quantifier) }\end{array}$ & $\begin{array}{r}\text { English gloss } \\
\text { Verb+Ind qua }\end{array}$ & Free English translation \\
\hline a. Siebie & sie + bie & keep + some & reserve some resources \\
\hline b. Kabie & ka + bie & say + some & make some comments \\
\hline c. Selebie & sele + bie & laugh + some & engage in some laughter \\
\hline
\end{tabular}

In the discussions that follow, I turn to examine the interaction of Nzema derivational and inflectional processes with the internal structure of pet names in sections 3.1.3 and 3.1.4 respectively.

\subsubsection{Derivational Processes in Nzema 'Pet Names'}

Katamba (1993) and Yule (2010) are of the view that words that exist in a language consist of elements known as morphemes; the minimal indivisible units of meaning or grammatical function. Morphemes, according to Mensah (2010), are principally free or bound; free morphemes can stand on their own and make sense whereas bound morphemes do not have independent existence, rather, they have semantic content only in the context of free morphemes (Mensah, 2010: 258). Bound morphemes which signal the creation of new lexical categories from existing ones are derivational morphemes (see Thakur, 1997; Mensah, 2010). In Nzema derivational processes, the suffixes $\{\boldsymbol{- v o l} \boldsymbol{\varepsilon}\}$ and $\{\boldsymbol{- n l i}\}$ are identified as able to change one lexical category to another. In this paper, however, the data proved instances of the derivational suffix $\{-\mathbf{v o l} \mid \boldsymbol{\varepsilon}\}$, attached to root verbs to obtain nominal counterparts as exemplified below in table 8:

Table 8 Derivational process in Nzema pet names

\begin{tabular}{|c|c|c|c|}
\hline Pet name & $\begin{array}{l}\text { Morphological component } \\
\quad \text { (Root verb + Suffix) }\end{array}$ & $\begin{array}{l}\text { English gloss } \\
\text { (Verb + Suffix })\end{array}$ & Derived noun \\
\hline a. Boavole & boa + vole & help + suffix $\{$-er $\}$ & helper \\
\hline b. Kakyevole & kakye + vole & remind + suffix $\{$-er $\}$ & reminder \\
\hline c. Kpəvole & kpJ + vole & hate + suffix $\{$-er $\}$ & enemy \\
\hline
\end{tabular}

\subsubsection{Inflectional Processes in Nzema 'Pet Names'}

Mensah (2010) avers that bound morphemes which signal grammatical categories such as tense, aspect, person, number, and negation are said to be inflectional. In the morphology of Nzema, prefixes such as $\{\mathbf{a}-, \mathbf{n}-$, $\mathbf{m}-, \mathbf{n}-\}$ are bound morphemes that are attached to root/base morphemes to indicate number. For instance, the plural form of the lexical noun baka 'tree' becomes mbaka 'trees', while that of taboa 'wood' becomes ndaboa 'woods' and kila 'mouse' becomes ggila 'mice' through a homorganic nasal assimilation'. The suffixes $\{-\mathrm{ma}\}$ and $\{-$ le\} also indicate number and tense respectively in the word structure of Nzema. All these bound morphemes identified above are class maintaining affixes in the sense that they do not change the lexical category (word class) of the root word they may be attached. In the data, however, only the plural marker $\{$-ma $\}$ was seen to be attached to some nouns to indicate number/quantity. Table 9 is an illustration of the inflectional processes in Nzema pet names.

\footnotetext{
${ }^{5}$ Katamba (1989) and Tilahun (2014) describe homorganic nasal rule as a process in which the place of articulation of an initial sound of a word is assimilated by the final sound in a prefix.
} 
Table 9 Inflectional process in Nzema pet names

\begin{tabular}{|l|c|c|c|}
\hline \multicolumn{1}{|c|}{ Pet name } & $\begin{array}{c}\text { Morphological component } \\
\text { (Root noun + Suffix) }\end{array}$ & $\begin{array}{c}\text { Free English gloss } \\
\text { (Noun + plural marker) }\end{array}$ & $\begin{array}{c}\text { Inflected } \\
\text { noun }\end{array}$ \\
\hline a.Nwodomgboma & nwodomgbo + ma & gossip + plural marker $\{-\mathrm{s}\}$ & gossips \\
\hline b. Gyantzlama & gyantzla $+\mathrm{ma}$ & prostitute + pl marker $\{-\mathrm{s}\}$ & prostitutes \\
\hline c. Kodiawuma & kodiawu $+\mathrm{ma}$ & murderer + pl marker $\{-\mathrm{s}\}$ & murderers \\
\hline
\end{tabular}

\subsubsection{Borrowed Words as 'Pet Names' in Nzema}

Akpanglo-Nartey (2002) mentions that words that come from a particular source language to enter another language can be described as 'loan words'. Some of the pet names in Nzema were seen to be words that are borrowed from English ${ }^{6}$. Examples are shown in table 10:

Table 10 English words used as pet names in Nzema

\begin{tabular}{|cl|}
\hline a. & Hope \\
\hline b. & Peace \\
\hline c. & Lucky \\
\hline d. & Wisdom \\
\hline e. & Victor \\
\hline f. & Prosper \\
\hline g. & Boss \\
\hline h. & Captain \\
\hline i. & Paradise \\
\hline j. & Beautiful \\
\hline
\end{tabular}

\subsubsection{Reduplicated Pet Names}

The data further revealed the prevalence of reduplicated morphemes; which are also English lexemes that had undergone total reduplication. Interestingly, some of the words (names) in this category tend to reflect the nature, colour and behaviour of the animal that is named. These pet names are exemplified in table 11:

Table 11 Nzema pet names as reduplicated morphemes

\begin{tabular}{|c|l|}
\hline Root word & Reduplicated form (pet name) \\
\hline a. Fast & Fast-fast \\
\hline b. Black & Black-black \\
\hline c. Shine & Shine-shine \\
\hline d. One & One-one \\
\hline e. Jack & Jack-jack \\
\hline
\end{tabular}

\subsection{SYNTACTIC ANAL YSIS OF 'PET NAMES' IN NZEMA}

Some of the pet names, though written together as single words, manifested as phrases and complete sentences. This section discusses Nzema pet names as phrases, imperatives, declaratives and interrogatives. Some pet names as compound and complex-embedded constructions are also examined.

\subsubsection{Phrasal 'Pet Names'}

Phrasal pet names, as the data showcased, are usually in the domain of noun phrases which have no finite verbs, and so they may not provide complete meaning. They are characterised by the incorporation of personal-

\footnotetext{
${ }^{6}$ Although these words in tables 10 and 11 can have their respective equivalence in Nzema, the data proved that some petowners rather resorted to and adopted such words to name their pets.
} 
possessive pronouns such as $m e$ 'my', $b \varepsilon$ 'their', $y \varepsilon$ 'our' etc. which serve as determiners. Some examples are indicated in table 12:

Table 12 Pet names as phrases
a. Medwek

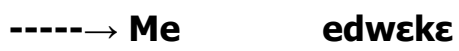
My.POSS case/problem
'My case'.
b. Meabusua $----\rightarrow$ Me abusua
My.POSS clan/family
'My clan/family'.
C. Begyezo ---- $\rightarrow$ B $\boldsymbol{\text { g }}$ gye They.POSS tooth.PL top
'On their teeth.

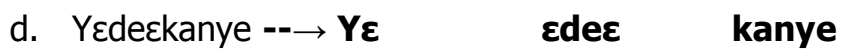
We.POSS kinsman really
'Our real kinsman'.

\subsubsection{Pet Names as Command (Imperative Constructions)}

The data showed that some pet names are in the imperative mood. They tend to instruct and provide directives. These names begin with base verbs; which have no explicit grammatical subject. The subject is represented by the second person pronoun woms 'you', which is implied. Through such names, the pet-owner advises individuals and the general public to be careful in life among other positive attitudes. The following are some examples in table 13 :

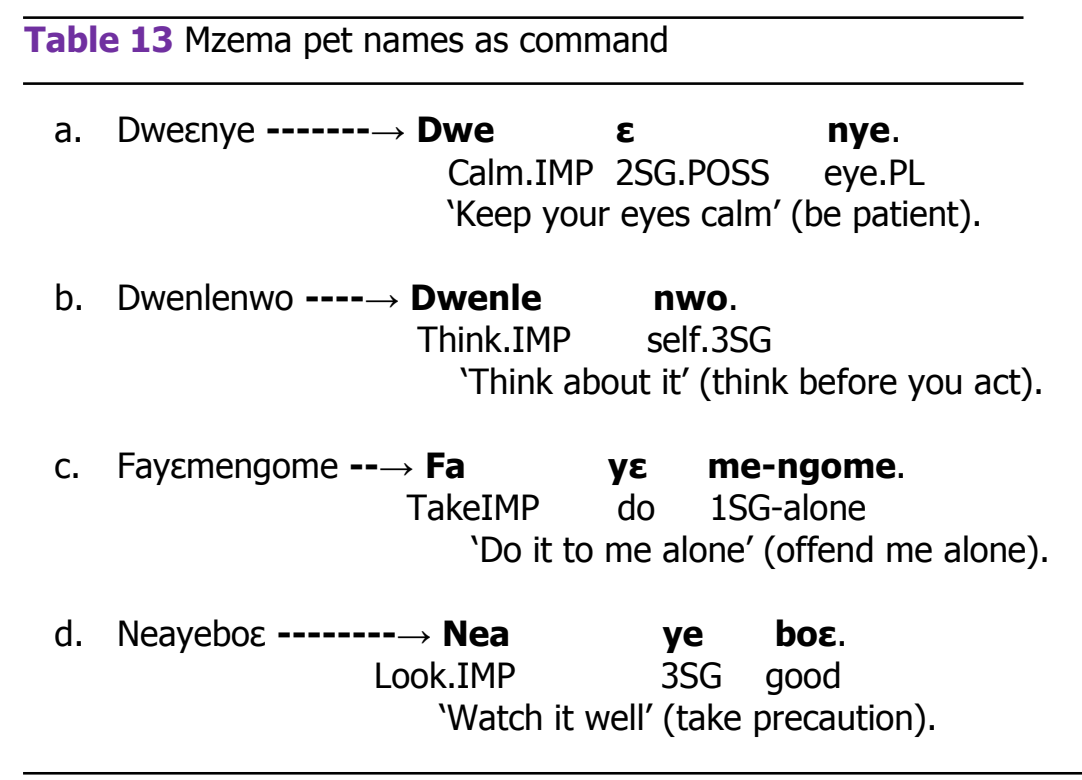

Some pet names further emerged as negative imperatives. A negative imperative construction in Nzema is marked by the inclusion of the morpheme $\{\mathbf{m m a}\}$, 'don' $\mathbf{t}$ ' in the sentence construction, which often occurs at sentence initial, preceding the base verb (see Kwaw, 2008b). Let us see examples from the data in table 14 : 


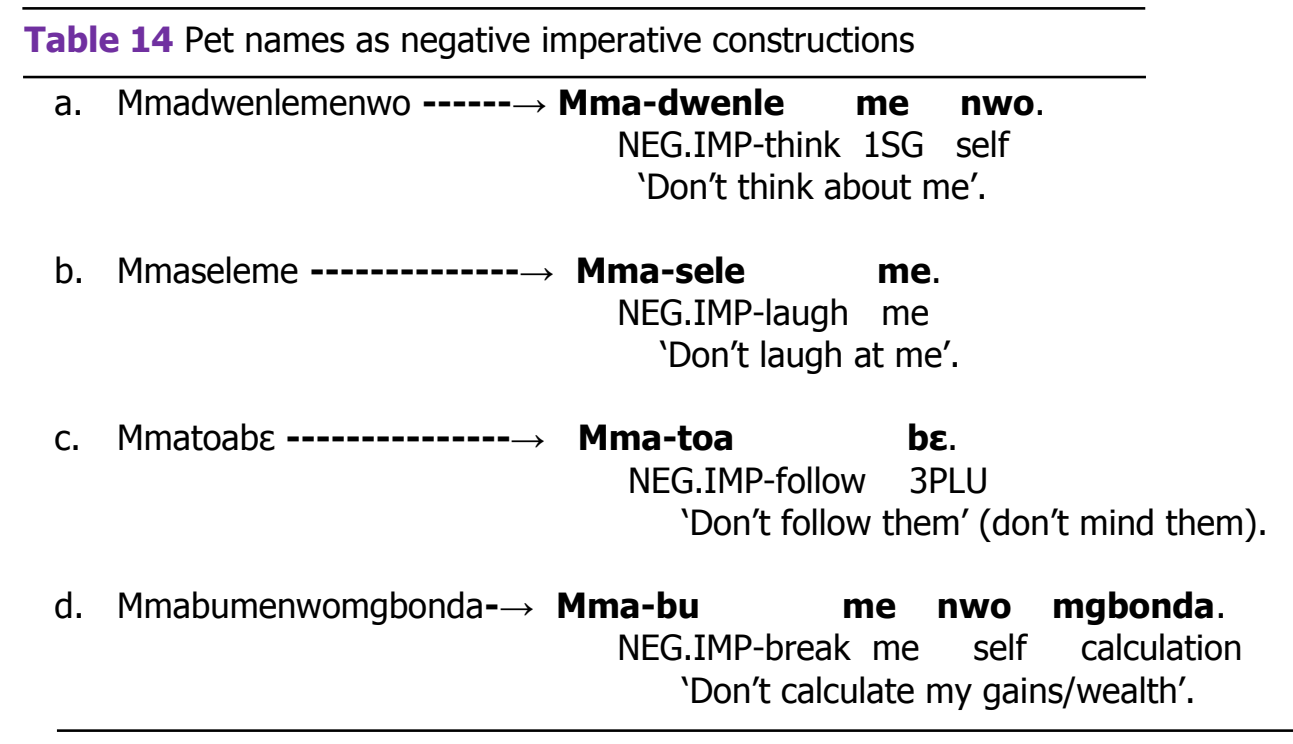

\subsubsection{Pet Names as Statement}

The data also revealed instances of pet names with declarative statements, which are assertive and seek to provide information of some sort. The formation of a simple declarative sentence involves a subject preceding the verb and its complement or adjunct (Atintono, 2013; Annan, 2014). These pet names basically constitute subject predicate constructions with overt grammatical subject-agent constituents. These are examined in table 15:

Table 15 Nzema pet names as declarative statement

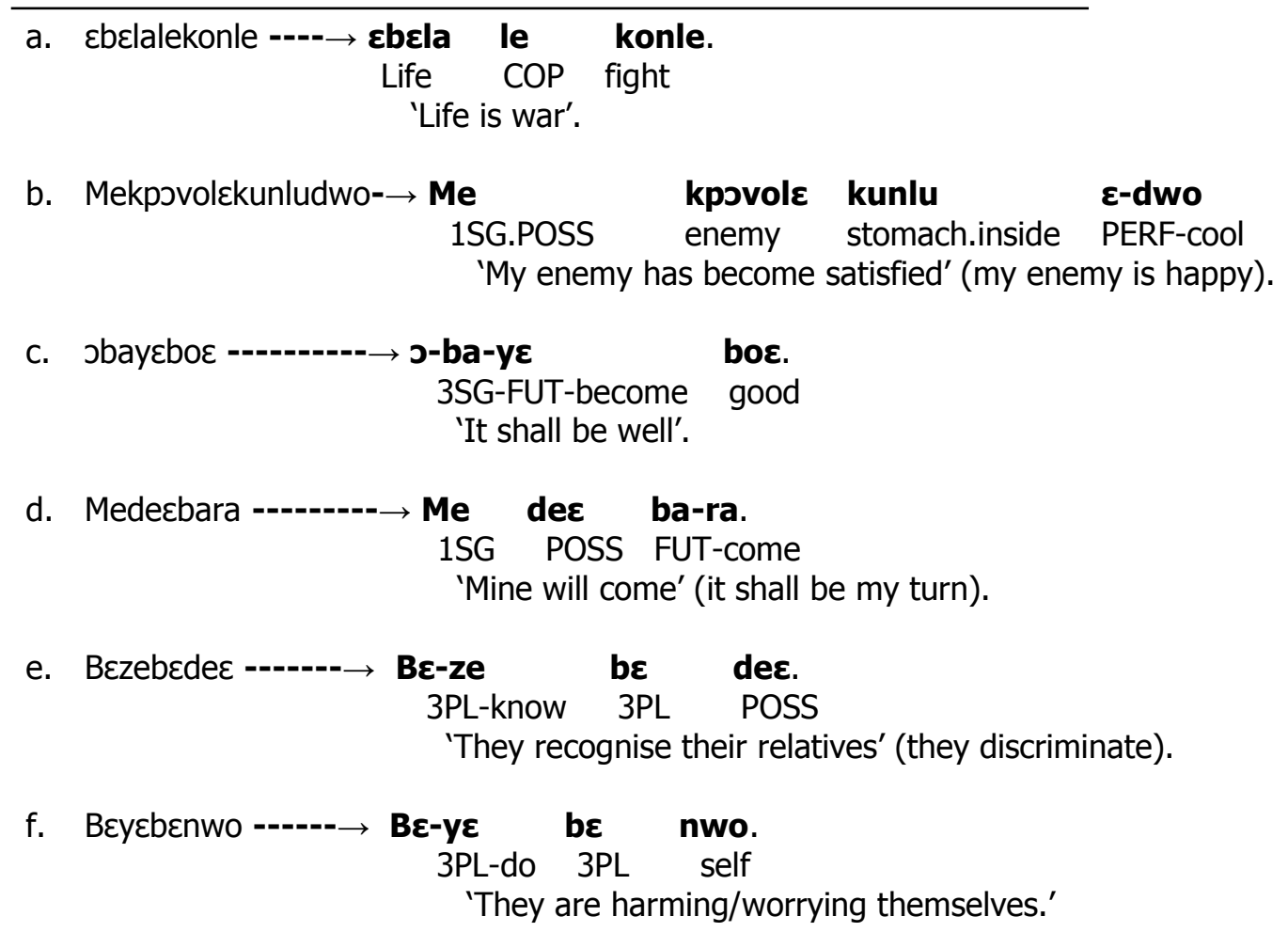

Besides the affirmative statements shown in table 15 , the data also displayed negative declarative constructions. In Nzema, a negative statement is characterised by the inclusion of negative markers $\{\mathbf{n}\}$ and $\{\mathbf{t} \boldsymbol{\varepsilon}\}$, which means 'not'. Table 16 below displays instances of pet names with negative assertion. 


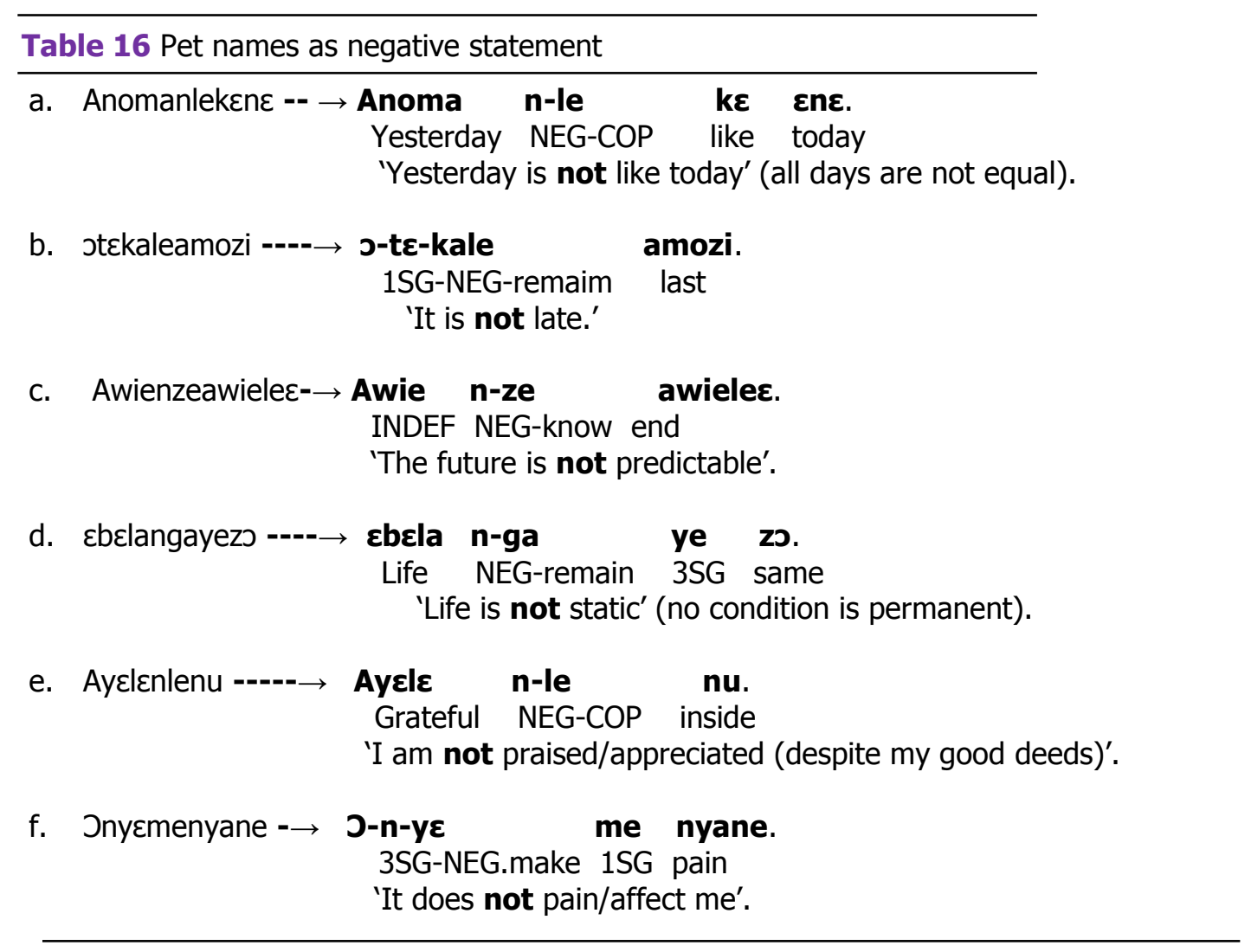

\subsubsection{Pet Names as Questions}

Another syntactic function that was prevalent in the data is interrogative sentence construction; which appears to seek certain information from an addressee (cf. Aarts, 2001; Biber et al., 2002; Annan, 2014). The data specifically revealed the wh-question type; which is marked in Nzema by the question words boni 'which', nwane 'who', duzu 'what', and kenle nzu 'when'. The following are examples in table 17:

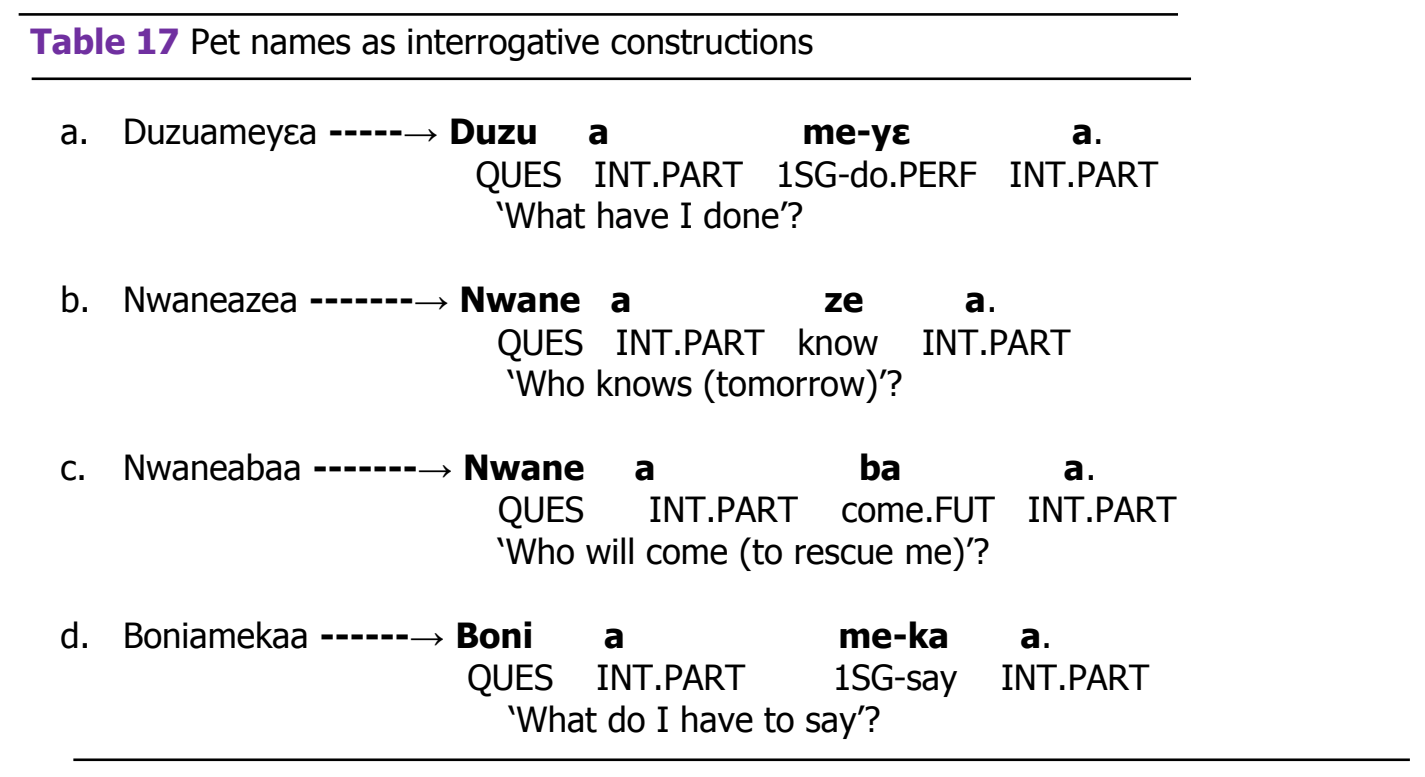




\subsubsection{Pet Names with Compound Sentence Structure}

A compound sentence involves the combination of two or more clauses of equal grammatical status with and, but, or etc. as coordinating conjunctions (see Crystal, 2007; Collins \& Hollo 2010). In the grammar of Nzema,

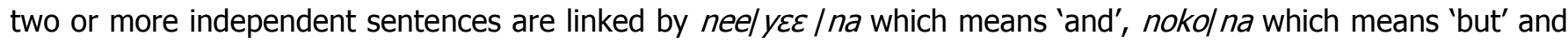
anzeE which means 'or' (Kwaw, 2008b). The data for this study, however, displayed instances of clausal coordinations with the use of na 'and' as well as na 'but'. Below are some examples:

Table 18 Pet names with compound sentence structure

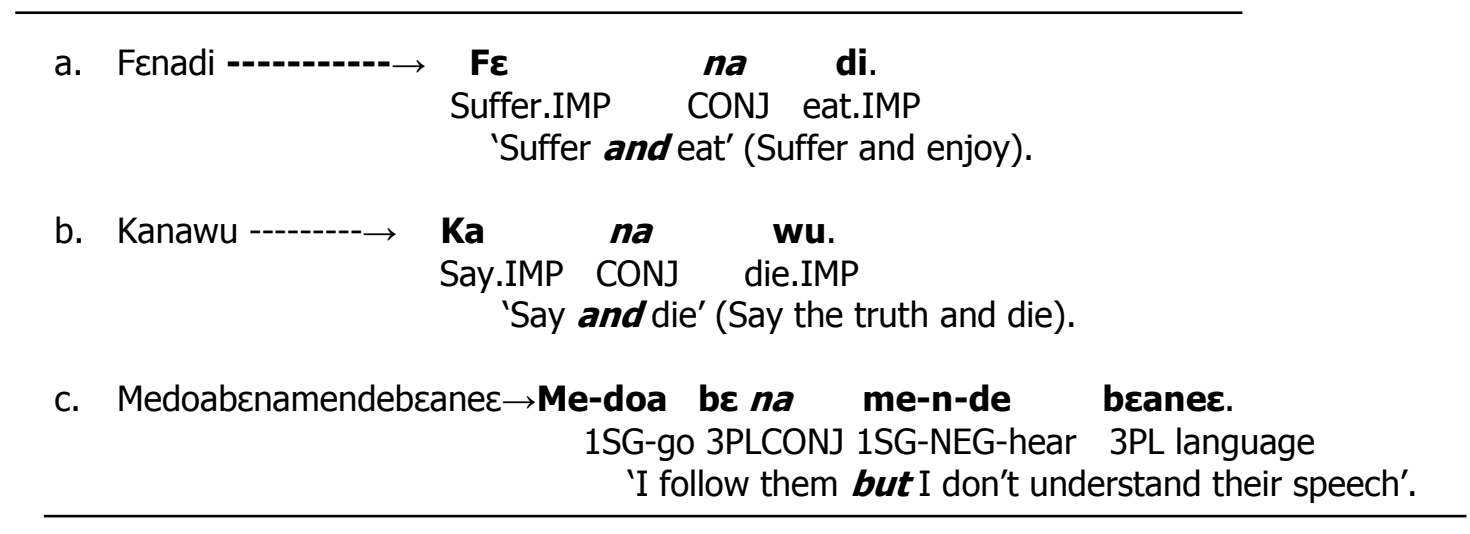

\subsubsection{Pet Names as Nominal Clause Construction}

A noun clause in Nzema, like in English and many other languages (Essuah, 1965: Kwaw, 2008b) is a subordinate (dependent) clause that makes meaning in the presence of a main (independent) clause. It is introduced by the subordinating conjunctions (complementizers) such as $k \varepsilon$ 'that', as well as 'what/whatever/whoever'. Some examples of pet name as nominal clauses are shown here in table 19:

Table 19 Pet names as nominal clauses

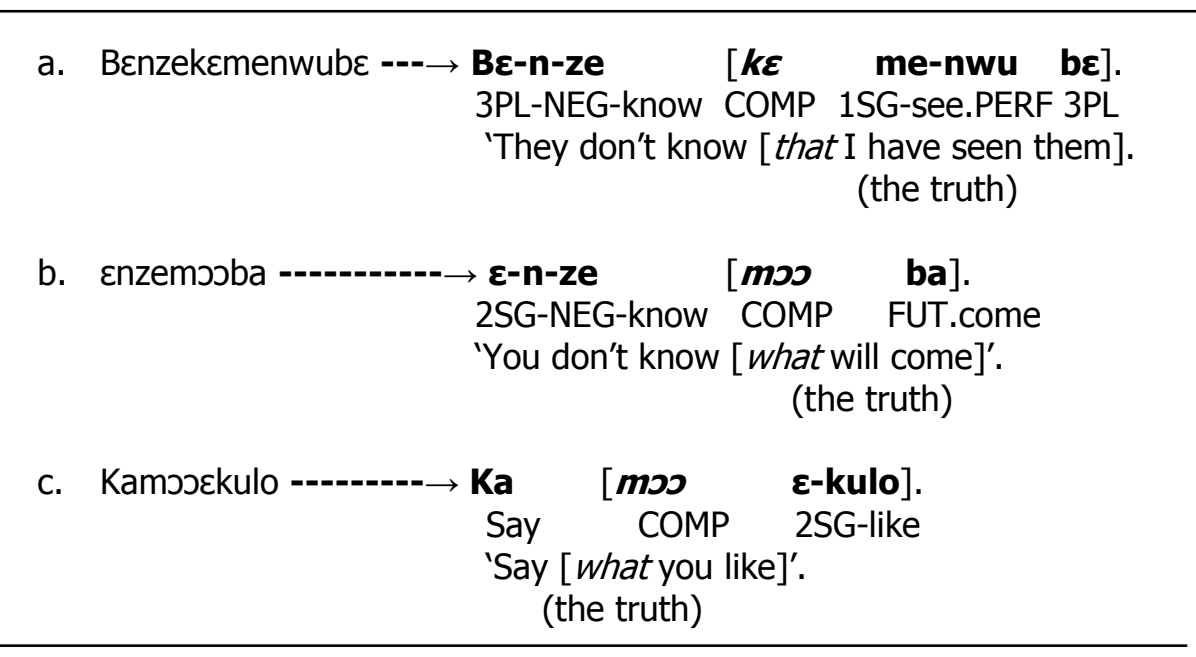

In (19a-c), the subordinate clauses are put in square bracket with the complementizers, $k \varepsilon$ 'that' and $m כ$ 'what' in italics. It is important to say that each of the subordinate clauses can be replaced by an NP such as nohale ne 'the truth'; which accounts for their description as nominal clauses. In (19a) and (19b), the subordinate nominal clauses function as the Object-patient of the verb ze 'know'. In (19c), the clause functions as Object-patient of the verb $k a$ 'say'. It is also observed that, since (19c) manifests as an imperative construction, the Subject-agent element is not overtly indicated; but it is implied and can be realised at the level of interpretation. 


\subsubsection{Pet Names as Conditional Clauses}

In the syntax of Nzema, a conditional clause construction is marked by the conditional subordinating conjunction (saa) 'if', which can be omitted, but the conditional particle..... $a$; is essential and obligatory, which is immediately followed by a comma to indicate the clause boundary between the main clause and subordinate clause (see Yakub, 2019b). Let us observe some examples of pet names as complex conditional clauses in table 20:

Table 20 Pet names as conditional clause
a. (Saa)cteammasele $-\rightarrow[($ Saa $) \quad \boldsymbol{\varepsilon}$-te
$a_{1}$ mma-sele.
COND 2SG-hear CON.PART NEG.IMP-laugh
'If you hear (my matter), don't laugh'.

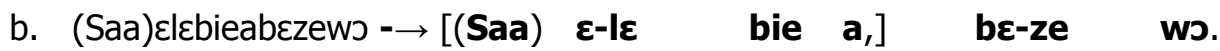 COND 2SG-have some CON.PART 3PL-know 2SG
'If you are wealthy, they recognise/regard you'.
c. (Saa)عdiasiebie ------ $\rightarrow[($ Saa $) \quad \varepsilon$-di $\quad$ a, $]$ sie bie. COND 2SG-eat CON.PART keep INDEF 'If you spend (your money), reserve some'.

d. (Saa)kkpomeawu $--\rightarrow\left[\left(\right.\right.$ Saa) $\quad$ e-kpo me $\left.\mathbf{a}_{1}\right]$ wu. COND 2SG-hate 1SG CON.PART die.IMP 'If you hate me, (you will) die'.

\section{Conclusions}

Adopting the Framework-free Grammatical Theory, the paper discussed the morphological and syntactic structures of pet names in Nzema. The findings showed that the morphological features of Nzema pet names include single root morphemes, lexical compounding, derivational and inflectional processes, as well as borrowed words and reduplicated morphemes. The syntactic analysis proved that Nzema pet names could function as declarative sentences, imperatives and interrogatives. Some of the pet names also constituted phrases, compound sentences, nominal and conditional clause constructions. Some of the compound names (see tables 2, 3 and 5) further showed phonological occurrences such as vowel elision and vowel harmony. It may be interesting to note that some pet names in Nzema are English words that had been adopted/borrowed, while completely reduplicating some English words as pet names (see tables 10 and 11). The findings from the analysis of the data have shown that names are not just oral construction of words to make reference to people and places; rather, names follow linguistic rules, i.e., the morphophonological and syntactic features of a particular language. Crucially, the study ascertained that pet names among the people of Nzema are also grammatically insightful; and can provide a window to understanding and appreciating the grammatical properties of the language. We find that pet names in Nzema reflect the people's sociocultural experience and the supernatural universe, which provide deep insight into their cultural patterns and tradition.

\section{ABBREVIATIONS USED

$\begin{array}{ll}\text { 1SG } & 1^{\text {st }} \text { Person Singular } \\ \text { 2SG } & 2^{\text {nd }} \text { Person Singular } \\ \text { 3SG } & 3 r^{\text {d }} \text { Person Singular } \\ \text { 3PL } & 3^{\text {rd }} \text { Person Plural } \\ \text { PL } & \text { Plural Marker } \\ \text { NEG } & \text { Negative marker } \\ \text { FOC } & \text { Focus Marker }\end{array}$




\begin{tabular}{ll}
\hline HAB & Habitual Marker \\
INT.PART & Interrogative Particle \\
CON.PART & Conditional Particle \\
PAST & Past Marker \\
PERF & Perfective Marker \\
POSS & Possessive Marker \\
IMP & Imperative \\
COP & Copula Verb \\
CONJ & Conjunction \\
COND & Conditional Marker \\
COMP & Complementizer \\
QUES & Question Word
\end{tabular}

\section{References}

Aarts, B. (2001), English Syntax and Argumentation. New York: Palgrave Macmillan.

Abdul, R. E. (2014), Synchronic Sociolinguistic Analysis of Personal Names among Ewes, Unpublished M.Phil Thesis, University Ghana.

Adomako, K. (2012), Vowel Raising in Akan Reduplication, Legon Journal of the Humanities. Vol. 23, 155-184.

Adomako, K. (2015), Truncation of Some Akan Personal Names, Journal of Language Studies, 15(1), 143-162. https://doi.org/10.17576/GEMA-2015-1501-09

Adomako, K. (2017), Morphophonological Analysis of Akan Female Family-Name Formation, Ghana Journal of Linguistics, 6(3), 1-32.

Agbo, M. S. (2014), Causativity in Igbo Personal Names, Journal of Universal Language, 15(2),1-33. https://doi.org/10.22425/jul.2014.15.2.1

Agyekum, K. (2018), Fictional Characters and Toponyms in Kwabena Adi's Brako, Ghana Journal of Linguistics, $7(2), 154-178$.

Agyekum, K. (2006), The Sociolinguistics of Akan Personal Names, Nordic Journal of African Studies, 15(2), 206 235.

Akpanglo-Nartey, J. N. (2002), An Introduction to Linguistics for Non-native Speakers of English, Accra: Sakumo Books.

Annan, J. C. (1980), The Phonology of Nzema, School of Ghana Languages, Ajumako. Unpublished Note.

Annan, J. C. (2014), Analysing and Using English, Accra: Lucky Four Publishers.

Ansu-Kyeremeh, K. (2000), Some Social Aspects of Bono Personal Names, Research Review, 16(2), 19-33.

Arloo, K. (2016), Sukoa Me: Nzema Grammar. Unpublished Note.

Atintono, A. S. (2013), The Semantics and Grammar of Positional Verbs in Gurene: A Typological Perspective, PhD Thesis, University of Manchester.

Awukuvi, E. M. \& Israel, P. C. (2018), An Onomastic Study of Selected Churches in Ghana, Journal of Language and Linguistics, 4, 37-64.

Baruah, T. C. (1991), The English Teacher's Handbook (3 ${ }^{\text {rd }}$ Ed). New Delhi: Sterling Publishers.

Batoma, A. (2006), African Ethnonyms and Toponyms: An Annotated Bibliography, Electronic Journal of Africana Bibliography, 10, 1-40. https://doi.org/10.17077/1092-9576.1000

Batoma, A. (2009), Onomastics and Indirect Communication among the Kabre of Northern Togo, Nordic Journal of African Studies, 18(2), 215-234.

Batoma, A. (2019), Onomastic Strategies: A Pragmatic Approach to the Use of Personal Names among the Kabye of Northern Togo, Sociolinguistics Studies, 13(2-4), 193-208. https://doi.org/10.1558/sols.37846 
Biber, D., Conrad, S. \& Leech, G. (2002), Student Grammar of Spoken and Written English, England: Pearson Education Ltd.

Caesar, R. O. (2019), A Morphosyntactic Analysis of Dangme Allusive Names, Journal of Universal Language, 20(2), 53-93. https://doi.org/10.22425/jul.2019.20.2.53

Collins, P. \& Hollo, C. (2010), English Grammar. An Introduction (2 ${ }^{\text {nd }}$ Ed). Palgrave Macmillan.

Crystal, D. (2007), A Dictionary of Linguistics and Phonetics (5 $5^{\text {th }}$ Ed), MA, USA: Blackwell Publishing.

Dakubu, M. (2000), Personal Names of the Dagomba, Research Review, 16(2), 53-65.

Dominic, C. (2014), The Sociocultural Study of Dagaare Personal Names, M.Phil Thesis, University of Education, Winneba, Ghana.

Egblewogbe, E. (1977), Ewe Personal Names: A Sociolinguistic Study, M.A Thesis, University of Ghana.

Ephratt, M. (1986), Is There a Grammar to Settlement Names? Lesonenu, 50, 137-150.

Essuah, J. E. (1965), Nzema Grammar. Ibadan: Claverianum Press.

Gerba, T. G. (2014), Morpho-semantic Analysis of Oromo Personal Names, International Journal of Innovative Research and \& Development, 3(13), 251-259.

Haspelmath, M. (2008), Framework-free Grammatical Theory, To Appear in: Heine, Bernd \& Narrog, Heiko (eds.). The Oxford Handbook of Grammatical Analysis. Oxford: Oxford University Press, Retrievable from https://www.eva.mpg.de>pdf.

Hedden, H. (2007), Arabic Names, The Indexer, 25(2), 9-15.

Jauro, L. B., Ngamsa, J., \& Wappa, J. P. (2013), A Morpho-semantic Analysis of the Kamue Personal Names, International Journal of English Language and Linguistics, 1(2), 1-12.

Jindayu, D. M. (2013), A Morpho-syntactic Analysis of Gonja Personal Names, M.Phil Thesis, University of Education, Winneba, Ghana.

Katamba, F. (1989), Introduction to Phonology, New York: Longman Publishing.

Katamba, F. (1993), Morphology, London: Pagrave Publishers Ltd.

Kwaw, F. E. (1999), The Phonology of Nzema Vowels, M.Phil Thesis, Tondhein, Norway.

Kwaw, F. E. (2008a), Maande $Y_{\varepsilon} \varepsilon$ Enloboc. Accra: Atwe Royal Consult Publishers.

Kwaw, F. E. (2008b), Nzema Aneemela Tagyee Ne. Accra: Atwe Royal Consult Publishers.

Kwesi, P. A. A. (1992), Nzema Anec Ne Anwo Mgbanyidweke. Accra: Bureau of Ghana Languages.

Lawson, E. D., Sheil, R. E., \& Nuessel, F. (2014), French Personal Names, The Onomastic Treasure of the CIA Chapter: 11, Editors: Edwin D. Lawson, Richard F. Sheil.

Lawson, E. D., \& Sheil, R. E. (2016), Turkish Personal Names, Retrievable from https://www.researchgate.net>2944. https://doi.org/10.13140/RG.2.1.2412.2646

Mensah, E. (2010). A Morpho-syntactic Analysis of Efik Proverbs, An Interdisciplinary Journal, 250-280

Mensah, E. \& Offong, I. (2013), The Structure of Ibibio Death-prevention Names, Anthropological Notebooks, 19(3), 41-59.

Mensah, E. (2015), Personal Names in Language Contact Situations: A Case of Cross River, South-Eastern Nigeria. Acta Academica, 47(2), 102-138.

Mensah, E. \& Rowan, K. (2019a), African Anthroponyms: Sociolinguistic Currents and Anthropological Reflections, Sociolinguistics Studies, 13(2-4), 157-170. https://doi.org/10.1558/sols.37819

Mensah, E. \& Rowan, K. (2019b), Aspects of Traditional Tiv Naming Practices: A Sociocultural Account, Sociolinguistics Studies, 13(2-4), 209-230. 
Mphande, L. (2006), Naming and Linguistic Africanism in African-American Culture, Selected Proceedings of the $35^{\text {th }}$ Annual Conference on African Linguistics, 104-113. Somerville, MA: Cascadilla Press.

Nsoh, E. \& Atintono, A. (2010), Personal Names among Farifari Speakers of Northern Ghana, Journal of African Cultures and Languages, 1(1), 77-85.

Nyame, J. (2019), Hiatus Resolution in Nzema. M.Phil Thesis, University of Education, Winneba.

Obeng, S. G. (1998), Akan Death-prevention Names: A Pragmatic and Structural Analysis, Names, 46(3), 163-187. https://doi.org/10.1179/nam.1998.46.3.163

Obeng, S. G. (2001), African Anthroponymy: An Ethnopragmatic and Morphophonological Study of Personal Names in Akan and some African Societies, Munich, Germany: Lincom Europa.

Ogunwale, J. A. (2012), A Pragmalinguistic Analysis of Yoruba Personal Names, Journal of Literary Onomastics, 2(1), 24-34.

Olenyo, M. M. J. (2011), What is in a Name? An Analysis of the Semantics of Lulogooli Personal Names, International Journal of Humanities and Social Science. 1(20), 211-218.

Owu-Ewie, C. (2014), A Morpho-syntactic Analysis of Fante Habitation Names, International Journal of Humanities and Social Studies, 2(5), 232-243.

Suzman, S. M. (1994), Names as Pointer: Zulu Personal Naming Practices, Language in Society, 23, 253-272. https://doi.org/10.1017/S0047404500017851

Thakur, D. (1997), Morphology. New Delhi: Bharati Bhawan Publishers.

Tilahun, N. (2014), Homorganic Nasal Assimilation in Arsi-Bale Afan Oromo: A Non-Linear Phonology, Humanities and Social Sciences, 3 (4), 240-248. https://doi.org/10.11648/j.hss.20150304.13

Wiredu, F. (1999), Organized English Structure, Legon, Accra: Academic Publication (Ghana) Ltd.

Yakub, M. (2019a), On the Purpose of Pet Naming as a Reflection of Nzema Traditional Philosophy and Culture: An Ethno-pragmatic Account, Paper presented at the $12^{\text {th }}$ Linguistics Association of Ghana Conference, $31^{\text {st }}$ July - $2^{\text {nd }}$ August, 2019.

Yakub, M. (2019b), A Morpho-pragmatic and Structural Analysis of Nzema Proverbs, M.Phil Thesis, University of Education, Winneba.

Yuka, L. C. (2008), Lexical Computation: The Case of Lamnso Personal Names, California Linguistic Note, Volume XXXIII, No. 2, 1-24.

Yule, G. (2010), The Study of Language (4th Ed), New York: Cambridge University Press.

\section{Funding}

No funding was received for conducting this study.

\section{Conflict of interest}

The Author has no conflicts of interest to declare that they are relevant to the content of this article.

\section{About the License}

(C) The author 2020. The text of this article is open access and licensed under a Creative Commons Attribution 4.0 International License 